\section{HIV-positive patients in the intensive care unit}

To the Editor: We read the retrospective audit by Mkoko and Raine $^{[1]}$ on HIV-positive patients requiring intensive care unit (ICU) admission with great interest. Although we acknowledge that intensive care is a scarce resource in South Africa (SA), and clear guidelines are needed to assist clinicians to allocate resources appropriately, we cannot concur with the authors' conclusion that ICU care may have to be withheld from HIV patients with higher Acute Physiology and Chronic Health Evaluation II (APACHE II) scores and the need for organ support such as renal replacement therapy and inotropes. The authors also erroneously suggest that 'this is the first study that has determined the outcomes of HIV-positive adults admitted to an SA ICU'

In a prospective study performed by Balkema et al. ${ }^{[2]}$ in the same city (Cape Town, SA), during the same period and on a similar population, ICU mortality of all HIV patients was $38.9 \%$. ICU mortality was associated with an AIDS-defining diagnosis (odds ratio 7.97, $p=0.003$ ). Non-survivors had higher APACHE II scores (25.8 v. 18.6; $p=0.001)$ and lower mean admission CD4+ counts (102.5 v. 225.2 cells $/ \mu \mathrm{L} ; p=0.014)$. Multiple logistical regression analysis confirmed the independent predictive value of World Health Organization (WHO) stage IV disease $(p=0.008)$, lower mean CD4+ counts on admission $(p=0.057)$, and higher APACHE II scores $(p=0.010)$ on ICU mortality, and of WHO stage IV disease $(p=0.007)$ and higher APACHE II scores $(p=0.003)$ on 30 -day mortality. In a post hoc analysis, the same investigators retrospectively validated a simple six-point scoring system based on the presence of: (i) AIDS; (ii) a CD $4+$ count of $<50$ cells $/ \mu \mathrm{L}$; (iii) extrapulmonary tuberculosis; (iv) Pneumocystis carinii pneumonia; (v) septic shock; and (vi) renal dysfunction. More than $80 \%$ of patients with a score of $\geq 3$ died, and no patient with a score of $\geq 4$ survived. ${ }^{[3]}$

The ICU mortality in Mkoko and Raine's study ${ }^{[1]}$ was $25.3 \%$ in patients with a mean (standard deviation) APACHE II score of 21.6 (8.4). This would be anticipated, as the predicted mortality with an APACHE II score in the range of 20 - 24, regardless of HIV status, is up to $40 \%$. Moreover, the APACHE II score was designed as an estimate of mortality after 24 hours of ICU care and not as a guide to offer or withhold critical care. ${ }^{[4]}$ The need for inotropic support is also widely regarded as an independent predictor of mortality in HIV-negative ICU patients. The $47 \%$ mortality described in the study would therefore also be anticipated and may not be indicative of mortality specifically attributable to HIV infection in this setting. ${ }^{[5]}$

We therefore cannot concur with the authors' interpretation to 'withhold' ICU care in only the HIV population with these general critical illness severity indices. In the absence of randomised studies or higher levels of evidence, it is still safer to discuss referrals on a case-by-case basis and to consider all comorbidities.

\section{A Parker}

Division of Infectious Diseases, Department of Medicine, Faculty of Medicine and Health Sciences, Stellenbosch University and Tygerberg Academic Hospital, Cape Town, South Africa

aparker@sun.ac.za

\section{S Lahri}

Department of Emergency Medicine, Khayelitsha Hospital, Cape Town, South Africa

\section{J J Taljaard}

Division of Infectious Diseases, Department of Medicine, Faculty of Medicine and Health Sciences, Stellenbosch University and Tygerberg Academic Hospital, Cape Town, South Africa

\section{F N Koegelenberg}

Division of Pulmonology, Department of Medicine, Faculty of Medicine and Health Sciences, Stellenbosch University and Tygerberg Academic Hospital, Cape Town, South Africa

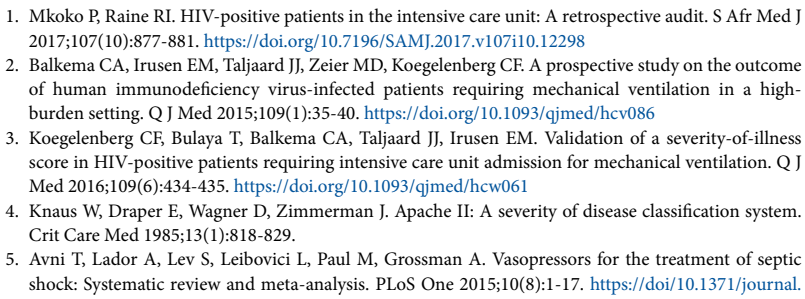

2. Balkema CA, Irusen EM, Taljaard JJ, Zeier MD, Koegelenberg CF. A prospective study on the outcome of human immunodeficiency virus-infected patients requiring mechanical ventilation in a highburden setting. Q J Med 2015;109(1):35-40. https://doi.org/10.1093/qjmed/hcv086

3. Koegelenberg CF, Bulaya T, Balkema CA, Taljaard JJ, Irusen EM. Validation of a severity-of-illnes score in HIV-positive patients requiring intensive care unit admission for mechanical ventilation. Q J Med 2016;109(6):434-435. https://doi.org/10.1093/qjmed/hcw061

4. Knaus W, Draper E, Wagner D, Zimmerman J. Apache II: A severity of disease classification system. Crit Care Med 1985;13(1):818-829.

5. Avni T, Lador A, Lev S, Leibovici L, Paul M, Grossman A. Vasopressors for the treatment of septic shock: Systematic review and meta-analysis. PLoS One 2015;10(8):1-17. https://doi/10.1371/journal. pone. 0129305

S Afr Med J 2017;107(11):929. DOI:10.7196/SAMJ.2017.v107i11.12907 